\title{
Towards a core outcome set for hemorrhoidal disease-a systematic review of outcomes reported in literature
}

\author{
R. R. van Tol $^{1} \cdot$ E. van Zwietering ${ }^{1} \cdot$ J. Kleijnen $^{2} \cdot$ J. Melenhorst $^{1} \cdot$ L. P. S. Stassen ${ }^{1} \cdot$ C. D. Dirksen ${ }^{3} \cdot$ S. O. Breukink $^{1,4}$
}

Accepted: 4 April 2018 / Published online: 22 April 2018

(C) The Author(s) 2018

\begin{abstract}
Purpose Previously published literature regarding treatment of hemorrhoidal disease (HD) revealed a lack of uniform defined outcomes. These differences between outcomes among studies limit transparency and lead to incomparability of results. The aim of this study was to systematically list the types of outcomes used in HD studies. This list will be used to develop a core outcome set.

Methods We searched Medline (Pubmed), Embase (OVID), and Cochrane for interventional studies for adult patients with HD. Two authors independently identified and reviewed eligible studies. This resulted in a list of outcomes reported by each clinical trial. All outcomes were categorized using the conceptual framework OMERACT filter 2.0.

Results A total of 34 randomized controlled trials and prospective observational studies were included in this study. A total of 59 different types of outcomes were identified. On average, 5.8 different outcomes (range 2-8) were used per study. The outcomes were structured into three core areas and10 ten domains. The most commonly reported core area was pathophysiological manifestations including the domain symptoms, complications, and recurrence. The most frequently reported outcomes were pain (91\%), blood loss (94\%), prolapse (71\%), and incontinence (56\%). There was a high variation in definitions of the common outcomes. And often there was no definition at all.

Conclusion This study shows a substantial heterogeneity in the types of outcomes in HD studies. We provided an overview of the types of outcomes reported in HD studies and identified a list of potentially relevant outcomes required for the development of a COS.
\end{abstract}

Keywords Review $\cdot$ Core outcome set $\cdot$ Outcomes $\cdot$ OMERACT $\cdot$ Hemorrhoids

Electronic supplementary material The online version of this article (https://doi.org/10.1007/s00384-018-3046-2) contains supplementary material, which is available to authorized users.

S. O. Breukink

s.breukink@mumc.nl

1 Department of Surgery, Maastricht University Medical Centre, P. Debyelaan 25, 6202, AZ Maastricht, The Netherlands

2 Care and Public Health Research Institute, Department of Family Practice, Maastricht University, Universiteitssingel 40, 6229, ER Maastricht, the Netherlands

3 Care and Public Health Research Institute, Department of Clinical Epidemiology and Medical Technology Assessment, Maastricht University Medical Centre, P. Debyelaan 25, 6202, AZ Maastricht, The Netherlands

4 Academic Hospital Maastricht, PO box 5800, 6202, AZ Maastricht, The Netherlands

\section{Introduction}

Hemorrhoidal disease (HD) is the commonest anorectal problem. It affects $5-10 \%$ of the population with the highest prevalence in people being 45-65 years of age [1]. HD is usually classified by their location and by the severity of prolapse. The most widely accepted classification is Golighers' classification [2]. There is considerable variation in the way that $\mathrm{HD}$ is managed due to the lack of strong recommendations in treatment guidelines [3, 4]. Basic treatment of HD consists of diet, lifestyle changes, and application of topical ointments [5]. The next treatment modality is often an office-based procedure like rubber band ligation (RBL), sclerotherapy, or radiofrequency therapy [6-9]. In case of persistent symptoms and higher grade of HD, patients are usually treated with surgical solutions (e.g., a Doppler-guided hemorrhoidal artery ligation (DGHAL) [10], with or without Recto-Anal-Repair (RAR) [11-13], stapled hemorrhoidopexy [14, 15], or traditional hemorrhoidectomy [16]. 
Ideally, a meta-analysis will answer the question what the best current treatment option is for HD. This requires that the same types of outcomes are reported and assessed in the same way. However, previously published literature regarding HD highlighted the lack of uniform outcome definition, measurement, and reporting in research data $[6,17,18]$. In order to overcome this, the European Society of Coloproctology (ESCP) recognized the need to define a core outcome set (COS) for HD. A COS is an agreed standardized set of outcomes that should be assessed and reported in clinical trials for a specific clinical area [19].

Since 1992, the Outcome Measures in Rheumatology (OMERACT) group developed many core outcome sets (COSs) according to a framework and methodology (i.e., the OMERACT Filter) for the identification and validation of core outcome measurement sets for use in clinical trials for any health condition [20]. Also Core Outcome Measures in Effectiveness Trials (COMET) [21] and the International Consortium for Health Outcomes Measurement (ICHOM) $[22,23]$ initiatives developed a guideline for developing a COS.

We chose to follow the OMERACT working group, since their OMERACT filter resulted in successful development and implementation of core domain and measurement sets for many different diseases [24-30]. In addition, they recently provided the OMERACT Filter 2.0, a practical framework to develop and validate domains and measures for any health condition [31].

The aim of this systematic review was to provide an overview of the types of outcomes reported in studies regarding HD and to identify a list of potentially relevant outcomes for development of a COS.

\section{Methods}

\section{Literature search}

We conducted a search of standard electronic databases such as Medline (Pubmed), Embase (OVID), and Cochrane for relevant studies regarding hemorrhoidal disease. Boolean operators (AND, OR) were used to narrow and widen the search results. In addition, the reference list of the included studies was also searched for additional studies that were not identified in the database searches. Reviews were cross-checked to identify missing studies.

The search was limited to recent published studies between January 2012 and December 2016 representatively for all published studies. No language restrictions were imposed. The full search query is described in Appendix 1.

\section{Study selection}

For inclusion in the review, a study had to meet the following criteria: (1) both randomized controlled trials and (prospective) observational studies since outcomes may have not been reported in RCTs due to selective reporting bias, (2) studies had to assess basic treatment (i.e., diet, lifestyle, and physical therapy), office-based procedures (i.e., rubber band ligation, sclerotherapy, and infrared coagulation) or surgical treatment (i.e., DG-HAL with or without mucopexy, stapled haemorrhoidopexy, and the traditional hemorrhoidectomy) regarding hemorrhoidal disease, and (3) reporting at least one outcome.

\section{Data extraction}

Two authors (RT and EZ) independently screened the titles, abstracts, and full papers regarding the in- and exclusion criteria. Studies without data for retrieval or duplicate publications were excluded. Any disagreement in study selection was resolved by consensus or by discussion with a third reviewer (SB).

The same two authors independently extracted data from the included studies: study name, design, size, intervention(s), outcome, and outcome assessment (e.g., instrument). After completing the data extraction, the two independent reviewers discussed the results, and if discrepancy was present, a consensus was reached.

\section{Data synthesis}

Outcomes were categorized according to the framework of the OMERACT 2.0 filter $[32,33]$. The framework consisted of four levels including life impact, pathophysiological manifestations, resource use/economic impact, and death. See Fig. 1 for the conceptual framework.

\section{Results}

\section{Study selection}

The literature search resulted in 4863 abstracts (PubMed, 2717; Ovid, 2084; Cochrane, 62). After deduplication, 4295 records remained and were included in title and abstract screening. Title and abstract screening resulted in the inclusion of 216 articles for full-text screening. After this first step, 34 studies were included in the review. A PRISMA flow diagram of screening and inclusion of studies is shown in Fig. 2. The summary of the characteristics of the included studies according to their year of publication is shown in Appendix 2.

\section{Study characteristics}

Baseline characteristics of the included studies are displayed in Table 1. We identified 24 randomized controlled trials (RCTs) and ten observational studies. Most studies assessed 
Fig. 1 Conceptual framework OMERACT filter 2.0 [32]
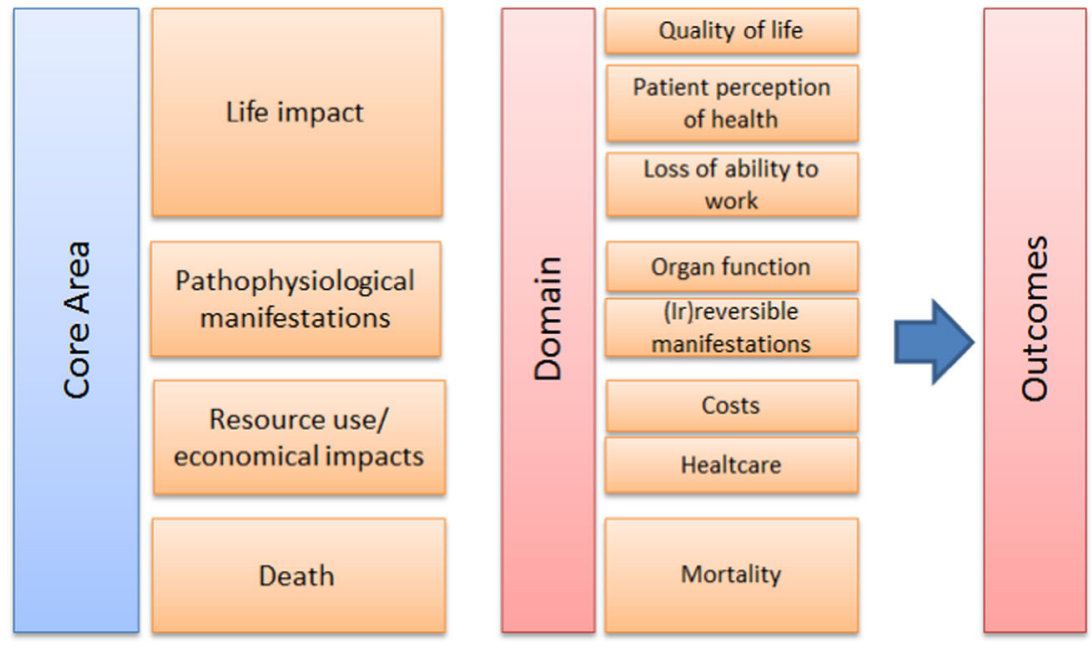

the effectiveness of surgical techniques (92\%). In total, 59 different outcomes were used in the 34 included studies. On the average, 5.8 different outcomes [1-6, 32] were assessed per study.

\section{Categorization of outcomes}

The 59 different types of outcomes were categorized into three core areas and 10 domains [Appendix 3: Outcomes structured into potential domains and core areas according to
OMERACT Filter 2.0]. The core area life impact included the following three domains: patient satisfaction, quality of life, and time to return to normal. The core area pathophysiological manifestations consisted of four domains: symptoms, complications, and recurrence. The core area resource use/ economical impact included four domains: duration of operation, duration of hospitalization, re-operation, and costs. No outcome could be placed into the core area death. Apparently, death was not an outcome of interest in hemorrhoidal studies. Therefore, this core area was excluded.
Fig. 2 PRISMA flow diagram [34]

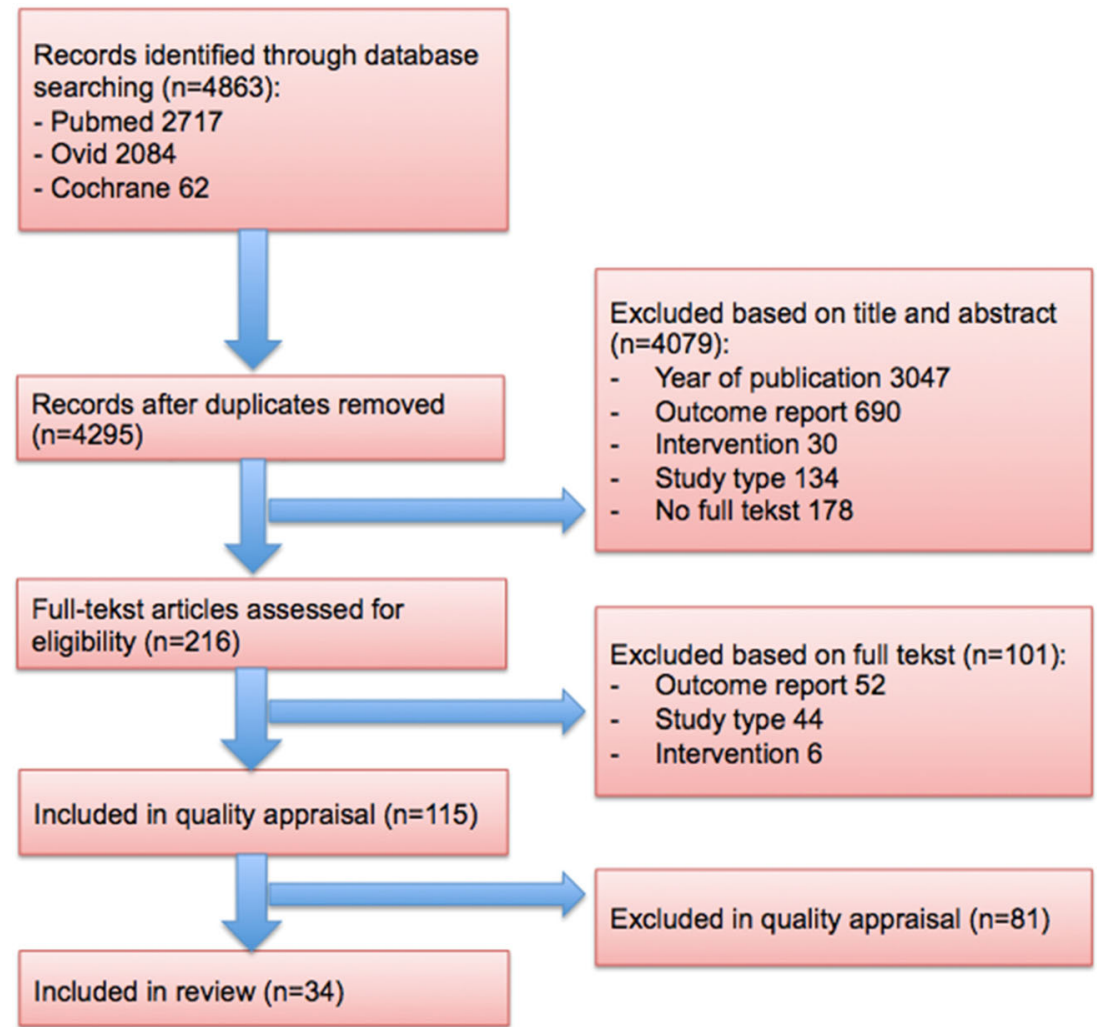


Table 1 Baseline characteristics of the included studiesBaseline characteristics of the included studies

\begin{tabular}{|c|c|c|}
\hline \multicolumn{3}{|l|}{ Baseline characteristics of the included studies } \\
\hline & & $N(\%)$ \\
\hline Total included studies & & $34(100)$ \\
\hline \multicolumn{3}{|l|}{ Study type } \\
\hline Randomized controlled trials & & $24(71)$ \\
\hline Observational studies & & $10(29)$ \\
\hline Treatment & Control & \\
\hline \multicolumn{3}{|l|}{ Surgical treatment } \\
\hline Hemorrhoidectomy & Hemorrhoidectomy & $4(12)$ \\
\hline Hemorrhoidectomy & Stapled hemorrhoidopexy & $5(15)$ \\
\hline Hemorrhoidectomy & DG-HAL (with suture mucopexy) & $5(15)$ \\
\hline Stapled hemorrhoidopexy & DG-HAL (with suture mucopexy) & $3(9)$ \\
\hline DG-HAL (with suture mucopexy) & Suture mucopexy & $3(9)$ \\
\hline Hemorrhoidectomy & - & $1(3)$ \\
\hline Stapled hemorrhoidopexy & - & $1(3)$ \\
\hline DG-HAL (+ RAR or suture mucopexy) & - & $6(18)$ \\
\hline \multicolumn{3}{|l|}{ Surgical vs office-based procedures } \\
\hline Hemorrhoidectomy & Sclerotherapy & $1(3)$ \\
\hline DG-HAL & Rubber band ligation & $1(3)$ \\
\hline DG-HAL & Infrared coagulation & $1(3)$ \\
\hline \multicolumn{3}{|l|}{ Office-based procedure } \\
\hline Sclerotherapy & - & $1(3)$ \\
\hline \multicolumn{3}{|l|}{ Basic treatment } \\
\hline Diltiazam gel & Placebo & $1(3)$ \\
\hline Flavenoids & Placebo & $1(3)$ \\
\hline Total different reported outcomes & & 59 \\
\hline Average number of outcomes per study & & 5.8 (range $3-8$ ) \\
\hline
\end{tabular}

Tables 2, 3, and 4 summarize the number of outcomes reported within each domain and the number of studies reporting these outcomes in each core area.

The most reported domains were symptoms (100\%), complications $(91 \%)$, recurrence $(59 \%)$, and patient satisfaction (41\%).

In office-based procedure and basic treatment studies, the most reported domains were similar including symptoms, complications, and patient satisfaction. Recurrence, time to return to normal, quality of life, duration of operation, re-operation, and costs, however, were no outcomes in these studies [Table 5].

Table 2 Outcome domains in 42 studies included according to OMERACT 2.0 filter core "Life impact"

\begin{tabular}{lll}
\hline Domain & $\begin{array}{l}\text { Number of outcomes } \\
\text { reported within } \\
\text { domain }\end{array}$ & $\begin{array}{l}\text { Number of studies } \\
\text { reporting outcomes } \\
\text { in domain }(\%)\end{array}$ \\
\hline Patient satisfaction & 1 & $14(41)$ \\
Time to return to normal & 6 & $12(35)$ \\
Quality of life & 2 & $8(24)$ \\
\hline
\end{tabular}

\section{Defining of outcomes}

Many outcomes were not clearly defined and assessed using non-validated questionnaires [Appendix 4: describes the type of outcome measurement and the used instruments].

\section{Core area life impact}

Patient satisfaction Patient satisfaction was used in 14 studies (41\%) and all studies used non-validated questionnaires.

Table 3 Outcome domains in 42 studies included according to OMERACT 2.0 filter core "Pathophysiological manifestations"

\begin{tabular}{lll}
\hline Domain & $\begin{array}{l}\text { Number of outcomes } \\
\text { reported within } \\
\text { domain }\end{array}$ & $\begin{array}{l}\text { Number of studies } \\
\text { reporting outcomes } \\
\text { in domain }(\%)\end{array}$ \\
\hline Symptoms & 22 & $34(100)$ \\
Complications & 18 & $31(91)$ \\
Recurrence & 2 & $20(59)$ \\
\hline
\end{tabular}


Table 4 Outcome domains in 42 studies included according to OMERACT 2.0 filter core "Resource use/economical impact"

\begin{tabular}{lll}
\hline Domain & $\begin{array}{l}\text { Number of outcomes } \\
\text { reported within } \\
\text { domain }\end{array}$ & $\begin{array}{l}\text { Number of studies } \\
\text { reporting outcomes } \\
\text { in domain }(\%)\end{array}$ \\
\hline Duration of operation & 3 & $10(29)$ \\
Duration of hospitalization & 2 & $13(38)$ \\
Re-operation & 2 & $13(38)$ \\
Costs & 1 & $5(15)$ \\
\hline
\end{tabular}

Time to return to normal Time to return to normal was used in 12 studies $(35 \%)$ and was defined as days off to work $(n=1)$, return to work $(n=2)$, resumption of social and working activity $(n=1)$, patients' time off everyday activity $(n=1)$, time to return to normal activity $(n=1)$, and sick leave $(n=1)$.

Quality of life The outcome quality of life or well-being was reported in eight studies (24\%). This domain was assessed by using a Visual Analog Scale $(n=1), \operatorname{SF}-12(n=2)$, or the EQ$5 \mathrm{D}(\mathrm{QALY})(n=1)$. In three other studies, assessment was not clear.

\section{Core area pathophysiological manifestations}

Symptoms Twenty-two different outcomes were used in a "symptom score." More than one outcome was used in each study (100\%). Most reported symptoms were pain (91\%), blood loss $(94 \%)$, and prolapse $(71 \%)$. Pain was assessed either by a visual analogue scale $(n=18)$, numeric rating scale (NRS) $(n=2)$, brief pain inventory (BPI), $(n=2)$, PATE 2000 $(n=1)$, or not clear $(n=8)$.

Blood loss was assessed using a 4-point scale from "not at all" to "blood dripping in toilet" $(n=1), 5$-point scale $(n=1)$, visual analog scale (VAS) $(n=1)$, Hemorrhoid symptom score
(HSS) $(n=1)$, requiring a re-intervention (transfusion, reoperation) $(n=3)$, or not clear $(n=25)$.

Prolapse was assessed using a 4-point scale: not at all/spontaneously/manual replacement/prolapse remains $(n=1), 5$-point scale $(n=1)$, PATE $2000(n=1)$, or not clear $(n=21)$.

Complications Eighteen different outcomes were used in a "complication score." In $91 \%$ of the studies, more than one outcome was used. The outcome incontinence was the most reported complication and assessed using 5-point scale ( $n=$ 1), Fecal Incontinence Quality of Life (Rockwood) Scale (FIQOL) $(n=2)$, the Wexner Incontinence Score $(n=2)$, Cleveland Clinic Florida Score $(n=2)$, Fecal Incontinence Quality-of-Life $(n=20$, the Vaizey Incontinence Score $(n=2)$, or not clear $(n=11)$.

Two studies provided a definition of complications: (1) deviation from normal perioperative course and (2) non-resolving adverse advents related to surgery.

Recurrence Recurrence was used in 20 studies (59\%). In nine studies, recurrence was assessed using non-validated questionnaires. One study assessing recurrent prolapse used anoscopic or proctoscopic examination $(n=1)$. In ten studies, the assessment of recurrence was not clear.

However, eleven studies (32\%) provided a definition, which varied considerably over studies: "recurrent prolapse and pain" $(n=2)$, "recurrent prolapse" $(n=1)$, "recurrence is based on patient's complaints and surgeon's examination" $(n=1)$, "physical examination" $(n=1)$, "relapse symptoms," "rectal bleeding and impression by the patient of recurrent prolapse" $(n=1)$, "internal hemorrhoids diagnosed on proctoscopy" ( $n=1)$, "1 year patient's self-reported assessment in combination with resource use from their general practitioner and hospital records" $(n=1)$, "clinical evident grade III at 1 year" ( $n=1)$, "recurrent prolapse or bleeding

Table 5 Comparison outcome domains between surgical, office-based, and basic treatment studies according to OMERACT 2.0 filter core.

\begin{tabular}{|c|c|c|c|}
\hline Domain & $\begin{array}{l}\text { Number of surgical studies } \\
\text { reporting outcomes in } \\
\text { domain }(\%)\end{array}$ & $\begin{array}{l}\text { Number of studies comparing surgical vs } \\
\text { office-based procedures reporting } \\
\text { outcomes in domain }(\%)\end{array}$ & $\begin{array}{l}\text { Number of basic treatment and } \\
\text { office-based procedure studies } \\
\text { reporting outcomes in domain }(\%)\end{array}$ \\
\hline Patient satisfaction & $11(39)$ & $1(33)$ & $2(67)$ \\
\hline Time to return to normal & $12(43)$ & 0 & 0 \\
\hline Quality of life & $7(25)$ & $1(33)$ & 0 \\
\hline Symptoms & $28(100)$ & $3(100)$ & $3(100)$ \\
\hline Complications & $26(93)$ & $2(67)$ & $3(100)$ \\
\hline Recurrence & $19(68)$ & $1(33)$ & 0 \\
\hline Duration of operation & $10(36)$ & 0 & 0 \\
\hline Duration of hospitalization & $11(39)$ & $1(33)$ & $1(33)$ \\
\hline Re-operation & $11(39)$ & $2(67)$ & 0 \\
\hline Costs & $3(11)$ & $2(67)$ & 0 \\
\hline
\end{tabular}


or PATE (recurrence of prolapse, acute symptoms, anal tone, and external pill)" $(n=1)$ or "reappearance of the condition at an equal or lower grade than before' $(n=1)$.

Core area resource use/economical impact Duration of operation was used as outcome in ten studies (29\%). Two studies assessed this outcome as incision to application of dressings $(n=1)$ and time between the incision and suturing the skin $(n=1)$.

Duration of hospitalization was used in 13 studies (38\%). In all studies, this outcome was not specified.

Re-operation was used in 13 studies (38\%). In none of the studies this outcome was specified.

Costs were used in five studies (15\%). In none of the studies, this outcome was specified.

\section{Discussion}

This systematic review showed a wide heterogeneity of outcomes in studies reporting on hemorrhoidal disease (HD). Furthermore, a lack of a standardized definition for commonly reported outcomes was observed.

The most commonly reported core area was pathophysiological manifestations including the domain symptoms, complications, and recurrence. All studies reported "symptoms" as an outcome (100\%). However, 22 different outcomes were used in this category alone, hence making direct comparison between studies difficult. Most reported symptoms were pain (91\%), blood loss (94\%), and prolapse (71\%). Pain and blood loss were the two pre-eminent symptoms that were addressed by asking the patient. Prolapse was assessed by asking both the patient (51\%) and by physical examination by the clinician (49\%). This disparity strengthens the case for the development of a COS which embraces the patient voice, as well as those from clinicians. Since patients are fulfilling a more central role in the consulting room, more areas of healthcare intent to develop patient-reported outcomes [35-37]. Until know, there are several non-validated symptom questionnaires developed for HD scoring the frequencies of five outcomes (i.e., pain, blood loss, prolapse, itching, and soiling), for example, the Sodergren score [38].

Besides symptoms, complications were reported in $91 \%$ of the studies. This Domain included 18 different outcomes. Again, heterogeneity of outcomes was seen within the studies. Registrations of complications are mandatory since reliable outcome data are crucial to improve outcome of care and gather credible data for benchmarking. In 1992, the Clavien-Dindo classification was introduced offering the possibility to combine grades of complications [39] which enables comparisons to be made between studies. Recurrence was the next frequently reported outcome in the studies $(59 \%)$ for the core area pathophysiological manifestations. Remarkable, only 11 studies (32\%) provided a definition, which varied considerably over studies.

The core area life impact capturing the domain patient satisfaction, time to return to normal, and quality of life was less often used in studies than pathophysiological manifestations. Patient satisfaction was the most reported domain in this core area. This domain was used in $41 \%$ of the studies and was always assessed by using non-validated questionnaires. In literature, no validated instrument for assessing patient satisfaction with HD treatment could be found. However, we think this domain is important as we know that dissatisfied patients often have worse clinical outcomes [40-43]. Time to return to normal was reported in $35 \%$ of the studies. Several definitions were provided in the studies. Quality of life was assessed in eight studies (24\%) and only three studies used a validated questionnaire (i.e., SF-12/36 and EQ5D).

The core area resource use/economical impact including duration of operation, duration of hospitalization, re-operation, and costs were also often used in studies. Duration of hospitalization was the most reported domain in this core area. Duration of hospitalization was used in 13 studies (38\%). In none of the studies, a definition was provided. Duration of operation was used as outcome in ten studies (29\%). Re-operation was used in 13 studies (38\%), but without providing a definition. Costs were used in five studies (15\%).

The OMERACT handbook states that the core area resource use is only recommended for inclusion if stakeholders decide that this core area is mandatory [33].

The core area death was not an outcome of interest in HD studies. Patients with HD are generally healthy patients undergoing elective medical therapy and therefore mortality due to treatment of HD is very rare.

Although HD is the most common anorectal problem, there is no core outcome set (COS) for this condition. This study supports the need to develop a COS for HD to ensure that study results can be compared and combined in the future. Next step will be a consensus study with both patients and healthcare professionals using the Delphi methodology [22]. With this review study, we have derived potentially relevant outcome domains for the development of such COS for HD (47).

Treating HD in daily practice includes often a combination of basic treatment, office-based procedures and surgical treatment, depending on the grade of severity of the disease. Therefore, we included all interventional studies in this review ranging from life styles and diet advices till surgical interventions. We recognize that in doing so, some outcomes (e.g. prolapse) may not be relevant for all types of treatment for HD, especially in lowgrade HD. Further, most domains were similar between the studies; however, the domains time to return to normal, quality of life, recurrence, duration of operation, re-operation, and costs were not reported in studies investigating only basic treatment or office-based procedures. This review can serve as a basis for 
developing a COS for all grades of HD; however, one should be aware of these findings.

The main limitation of our study is that in our search for outcomes, it has been limited to those reported in the existing literature, potentially missing outcomes that are important to other stakeholder groups, in particular patients. The importance of engaging patients in research is being increasingly recognized [44-46]. By asking patients which outcomes should be assessed, we can be confident that treatment interventions are investigated in a way that is relevant to the target population. Therefore, patients will be included in the consensus study. Secondly, the OMERACT Filter may have some limitations. It was developed primarily for trials within the field of rheumatology. Hence, there may be specialtyspecific factors that affect the suitability of the filter for other fields. Thirdly, in assigning outcomes to OMERACT core areas, we encountered several examples where an outcome term could potentially be assigned to more than one core area. For example, requirement of repeat procedure could be considered in the context of (ongoing) "Pathophysiological Manifestations," or within "Resource Use."

\section{Conclusion}

In Conclusion, this systematic review showed a wide heterogeneity of outcomes in studies reporting on hemorrhoidal disease (HD) and a lack of a standardized definition for commonly reported outcomes. To improve transparency between studies and facilitate the ability to compare and combine (future) studies, we need to develop a core outcome set (COS) for HD. This study, in which we identified a list of potentially relevant outcomes, is the first step towards the development of a COS for HD.

\section{Compliance with ethical standards}

Ethical approval None declared.

Conflict of interest The authors declare that they have no conflict of interest.

Open Access This article is distributed under the terms of the Creative Commons Attribution 4.0 International License (http:// creativecommons.org/licenses/by/4.0/), which permits unrestricted use, distribution, and reproduction in any medium, provided you give appropriate credit to the original author(s) and the source, provide a link to the Creative Commons license, and indicate if changes were made.

\section{References}

1. Lohsiriwat V (2012) Hemorrhoids: from basic pathophysiology to clinical management. World J Gastroenterol 18(17):2009-2017
2. Gerjy R, Lindhoff-Larson A, Nystrom PO (2008) Grade of prolapse and symptoms of haemorrhoids are poorly correlated: result of a classification algorithm in 270 patients. Color Dis 10(7):694-700

3. Higuero T, Abramowitz L, Castinel A, Fathallah N, Hemery P, Laclotte Duhoux C, Pigot F, Pillant-le Moult H, Senéjoux A, Siproudhis L, Staumont G, Suduca JM, Vinson-Bonnet B (2016) Guidelines for the treatment of hemorrhoids (short report). J Visc Surg. 153(3):213-218

4. Altomare DF, Roveran A, Pecorella G, Gaj F, Stortini E (2006) The treatment of hemorrhoids: guidelines of the Italian Society of Colorectal Surgery. Tech Coloproctol 10(3):181-186

5. Alonso-Coello P, Guyatt GH, Heels-Ansdell D, Johanson JF, Lopez-Yarto M, Mills E, Zhuo Q (2005) Laxatives for the treatment of hemorrhoids. Cochrane Database Syst Rev (4):CD004649. https://doi.org/10.1002/14651858.CD004649

6. Shanmugam V, Thaha MA, Rabindranath KS, Campbell KL, Steele RJ, Loudon MA (2005) Systematic review of randomized trials comparing rubber band ligation with excisional haemorrhoidectomy. Br J Surg 92(12):1481-1487

7. Brown S, Tiernan J, Biggs K, Hind D, Shephard N, Bradburn M, Wailoo A, Alshreef A, Swaby L, Watson A, Radley S, Jones O, Skaife P, Agarwal A, Giordano P, Lamah M, Cartmell M, Davies J, Faiz O, Nugent K, Clarke A, MacDonald A, Conaghan P, Ziprin P, Makhija R (2016) The HubBLe trial: haemorrhoidal artery ligation (HAL) versus rubber band ligation (RBL) for symptomatic secondand third-degree haemorrhoids: a multicentre randomised controlled trial and health-economic evaluation. Health Technol Assess 20(88):1-150

8. Tokunaga Y, Sasaki H, Saito T (2010) Evaluation of sclerotherapy with a new sclerosing agent and stapled hemorrhoidopexy for prolapsing internal hemorrhoids: retrospective comparison with hemorrhoidectomy. Dig Surg 27(6):469-472

9. Gupta PJ (2005) Ambulatory hemorrhoid therapy with radiofrequency coagulation. Clinical practice paper. Rom J Gastroenterol 14(1):37-41

10. Pucher PH, Sodergren MH, Lord AC, Darzi A, Ziprin P (2013) Clinical outcome following Doppler-guided haemorrhoidal artery ligation: a systematic review. Color Dis 15(6):e284-e294

11. Hoyuela C, Carvajal F, Juvany M, Troyano D, Trias M, Martrat A, Ardid J, Obiols J (2016) HAL-RAR (Doppler guided haemorrhoid artery ligation with recto-anal repair) is a safe and effective procedure for haemorrhoids. Results of a prospective study after two-years followup. Int J Surg 28:39-44

12. Faucheron JL, Trilling B, Reche F (2015) HAL-RAR(R) procedure: a safe operation for hemorrhoids. J Visc Surg 152(2):143-144

13. Faucheron JL, Poncet G, Voirin D, Badic B, Gangner Y (2011) Doppler-guided hemorrhoidal artery ligation and rectoanal repair (HAL-RAR) for the treatment of grade IV hemorrhoids: longterm results in 100 consecutive patients. Dis Colon rectum 54(2): 226-231

14. Giordano P, Gravante G, Sorge R, Ovens L, Nastro P (2009) Longterm outcomes of stapled hemorrhoidopexy vs conventional hemorrhoidectomy: a meta-analysis of randomized controlled trials. Arch Surg 144(3):266-272

15. Porrett LJ, Porrett JK, Ho YH (2015) Documented complications of staple hemorrhoidopexy: a systematic review. Int Surg 100(1):44 57

16. $\mathrm{Xu} \mathrm{L,} \mathrm{Chen} \mathrm{H,} \mathrm{Lin} \mathrm{G,} \mathrm{Ge} \mathrm{Q} \mathrm{(2015)} \mathrm{Ligasure} \mathrm{versus} \mathrm{Ferguson}$ hemorrhoidectomy in the treatment of hemorrhoids: a metaanalysis of randomized control trials. Surg Laparose Endosc Percutan Tech 25(2):106-110

17. Shao WJ, Li GC, Zhang ZH, Yang BL, Sun GD, Chen YQ (2008) Systematic review and meta-analysis of randomized controlled trials comparing stapled haemorrhoidopexy with conventional haemorrhoidectomy. Br J Surg 95(2):147-160 
18. Simillis C, Thoukididou SN, Slesser AA, Rasheed S, Tan E, Tekkis PP (2015) Systematic review and network meta-analysis comparing clinical outcomes and effectiveness of surgical treatments for haemorrhoids. Br J Surg 102(13):1603-1618

19. Klokker L, Tugwell P, Furst DE, Devoe D, Williamson P, Terwee CB et al (2016) Developing an OMERACT core outcome set for assessing safety components in rheumatology trials: the OMERACT safety working group. J Rheumatol. https://doi.org/ 10.3899/jrheum. 161105

20. Boers M, Brooks P, Strand CV, Tugwell P (1998) The OMERACT filter for outcome measures in rheumatology. J Rheumatol 25(2): 198-199

21. Prinsen CA, Vohra S, Rose MR, King-Jones S, Ishaque S, Bhaloo $\mathrm{Z}$ et al (2014) Core outcome measures in effectiveness trials (COMET) initiative: protocol for an international Delphi study to achieve consensus on how to select outcome measurement instruments for outcomes included in a "core outcome set". Trials 15:247

22. Ong WL, Schouwenburg MG, van Bommel ACM, Stowell C, Allison KH, Benn KE, Browne JP, Cooter RD, Delaney GP, Duhoux FP, Ganz PA, Hancock P, Jagsi R, Knaul FM, Knip AM, Koppert LB, Kuerer HM, McLaughin S, Mureau MAM, Partridge AH, Reid DP, Sheeran L, Smith TJ, Stoutjesdijk MJ, Vrancken Peeters MJTFD, Wengström Y, Yip CH, Saunders C (2017) A standard set of value-based patient-centered outcomes for breast cancer: the international consortium for health outcomes measurement (ICHOM) initiative. JAMA Oncol 3(5):677-685

23. McNamara RL, Spatz ES, Kelley TA, Stowell CJ, Beltrame J, Heidenreich P et al (2015) Standardized outcome measurement for patients with coronary artery disease: consensus from the international consortium for health outcomes measurement (ICHOM). J Am Heart Assoc 4(5):e001767

24. Hall NJ, Kapadia MZ, Eaton S, Chan WW, Nickel C, Pierro A et al (2015) Outcome reporting in randomised controlled trials and metaanalyses of appendicitis treatments in children: a systematic review. Trials 16:275

25. Schmitt J, Spuls PI, Thomas KS, Simpson E, Furue M, Deckert S, Dohil M, Apfelbacher C, Singh JA, Chalmers J, Williams HC, HOME initiative collaborators (2014) The Harmonising outcome measures for eczema (HOME) statement to assess clinical signs of atopic eczema in trials. J Allergy Clin Immunol 134(4):800-807

26. Mackie SL, Twohig H, Neill LM, Harrison E, Shea B, Black RJ, Kermani TA, Merkel PA, Mallen CD, Buttgereit F, Mukhtyar C, Simon LS, Hill CL, on behalf of the OMERACT PMR Working Group (2017) The OMERACT core domain set for outcome measures for clinical trials in polymyalgia rheumatica. J Rheumatol 44: $1515-1521$

27. Toupin-April K, Barton J, Fraenkel L, Li LC, Brooks P, De Wit M et al (2017) Toward the development of a core set of outcome domains to assess shared decision-making interventions in rheumatology: results from an OMERACT Delphi survey and consensus meeting. J Rheumatol 44:1544-1550

28. Hatemi G, Meara A, Ozguler Y, Direskeneli H, Mahr A, Easley E, Gurcan M, Davis T, Gul A, Yazici Y, Zottenberg K, Esatoglu SN, Erer B, Kamali S, Yazici H, Cronholm PF, Merkel PA (2017) Developing a core set of outcome measures for Behcet disease: report from OMERACT 2016. J Rheumatol 44:1750-1753

29. Singh JA, Dowsey M, Choong PF (2017) Patient endorsement of the outcome measures in rheumatology (OMERACT) total joint replacement (TJR) clinical trial draft core domain set. BMC Musculoskelet Disord 18(1):111
30. Singh JA, Dowsey MM, Dohm M, Goodman SM, Leong AL, Scholte Voshaar MM et al (2017) Achieving consensus on total joint replacement trial outcome reporting using the OMERACT filter: endorsement of the final core domain set for total hip and total knee replacement trials for endstage arthritis. J Rheumatol 44: $1723-1726$

31. Boers M, Kirwan JR, Wells G, Beaton D, Gossec L, d'Agostino MA, Conaghan PG, Bingham CO III, Brooks P, Landewé R, March L, Simon LS, Singh JA, Strand V, Tugwell P (2014) Developing core outcome measurement sets for clinical trials: OMERACT filter 2.0. J Clin Epidemiol 67(7):745-753

32. Kirwan JR, Boers M, Tugwell P (2014) Updating the OMERACT filter at OMERACT 11. J Rheumatol 41(5):975-977

33. Kirwan JR, Boers M, Hewlett S, Beaton D, Bingham CO 3rd, Choy E et al (2014) Updating the OMERACT filter: core areas as a basis for defining core outcome sets. J Rheumatol 41(5):994-999

34. Stovold E, Beecher D, Foxlee R, Noel-Storr A (2014) Study flow diagrams in Cochrane systematic review updates: an adapted PRISMA flow diagram. Syst Rev 3:54

35. Liu N, Lv J, Liu J, Zhang Y (2017) The PU-PROM: a patientreported outcome measure for peptic ulcer disease. Health Expect 20:1350-1366

36. Most SP, Moubayed SP (2017) Patient-reported outcome measures for facial plastic surgery: a specialty finally gets to go to the PROM. JAMA Facial Plast Surg 19(2):101

37. Klingels K, Mayhew AG, Mazzone ES, Duong T, Decostre V, Werlauff U, Vroom E, Mercuri E, Goemans NM, The Upper Limb Clinical Outcome Group (2017) Development of a patientreported outcome measure for upper limb function in Duchenne muscular dystrophy: DMD upper limb PROM. Dev Med Child Neurol 59(2):224-231

38. Pucher PH, Qurashi M, Howell AM, Faiz O, Ziprin P, Darzi A, Sodergren MH (2015) Development and validation of a symptom-based severity score for haemorrhoidal disease: the Sodergren score. Color Dis 17(7):612-618

39. Clavien PA, Barkun J, de Oliveira ML, Vauthey JN, Dindo D, Schulick RD, de Santibañes E, Pekolj J, Slankamenac K, Bassi C, Graf R, Vonlanthen R, Padbury R, Cameron JL, Makuuchi M (2009) The Clavien-Dindo classification of surgical complications: five-year experience. Ann Surg 250(2):187-196

40. Mancuso CA, Salvati EA, Johanson NA, Peterson MG, Charlson ME (1997) Patients' expectations and satisfaction with total hip arthroplasty. J Arthroplast 12(4):387-396

41. Mahajan ST, Elkadry EA, Kenton KS, Shott S, Brubaker L (2006) Patient-centered surgical outcomes: the impact of goal achievement and urge incontinence on patient satisfaction one year after surgery. Am J Obstet Gynecol 194(3):722-728

42. Rao JK, Weinberger M, Kroenke K (2000) Visit-specific expectations and patient-centered outcomes: a literature review. Arch Fam Med 9(10):1148-1155

43. Lochman JE (1983) Factors related to patients' satisfaction with their medical care. J Community Health 9(2):91-109

44. Bredart A, Marrel A, Abetz-Webb L, Lasch K, Acquadro C (2014) Interviewing to develop patient-reported outcome (PRO) measures for clinical research: eliciting patients' experience. Health Qual Life Outcomes 12:15

45. Black N (2013) Patient reported outcome measures could help transform healthcare. BMJ (Clinical research ed) 346:f167

46. Marshall S, Haywood K, Fitzpatrick R (2006) Impact of patientreported outcome measures on routine practice: a structured review. J Eval Clin Pract 12(5):559-568 